\title{
Analysis Methods of RICH Core Element in Network Environment Based on Matrix Vector
}

\author{
Bo Wang \\ Ningbo College of Health Sciences, Ningbo, China \\ w_ang_b_o@126.com
}

\begin{abstract}
Keywords: network environment; core competence; $\mathrm{RICH}$; unknown parameters; vector matrix; dummy variable
\end{abstract}

\begin{abstract}
With the development of society, the international nursing also gets increasingly the attention from all walks of life, Chinese foreign-related nursing needs be geared to international standards. To improve the comprehensive quality of vocational foreign-realted nursing students, the most important point is to cultivate the core competence of vocational nursing students. This paper make a deep analysis on vocational nursing RICH course under the core competencies of nurses, and then conduct empirical analysis on foreign-related nursing RICH course in vocational under the network environment, and make empirical validation of RICH course. The final results show that, the RICH course under the environment of network can effectively improve the core competence of foreign-related nursing students in vocational.
\end{abstract}

\section{Introduction}

With China's continuous deepening of reform and opening up, more and more foreigners come to China, and more and more Chinese nursing staff will enter the world nursing talent market, medical workers will not only hear a variety of languages, but also in face of many cultures, various thinking ways, different life style, and concussion and challenge brought by a variety of philosophy of life. China's foreign-related nursing major really start in 1980s, is a relatively late start in professional disciplines, which makes China's foreign-related nursing professional development is still in the exploratory stage[1]. There are many researches on China's vocational foreign-related nursing, such as $\mathrm{Xu}$ Ying's English learning thoughts on foreign-related nursing, focuses on the analysis of students' English learning of China's foreign-related nursing and the corresponding problems. According to these problems, we need to take positive measures to promote their English ability; Xu Hongli, Bai Mengqing's thinking on cross-cultural nursing ability of foreign-related nursing pay attention to the English-speaking western countries, the medical care personnel training should emphasis on appropriate care of culture[1]. In their view, understanding from a patient view is the responsibility of the nursing staff; Liao Yahui according to the features of medical English, established the learning strategy to develop vocational foreign-related nursing, mainly analyzed along with the increasingly extensive international academic communication, the medical English has received more and more attention[2]. Hou Yaqiong's discussion on higher vocational students employment prospect and direction of foreign-related nursing major mainly analyzed the employment of foreign nursing. In the former research, it's not difficult to find that they all from the point of view of English researches, this paper from the network environment, based on nurses' core quality, make deep empirical analysis on vocational foreign-related nursing, which has the farreaching significance of related theoretical research and practical operation for China's foreignrelated nursing[3].

\section{The core competence analysis on vocational foreign-related nursing students}

A. The core competence analysis on vocational foreign-related nursing students

At present, the domestic teaching goal has not been standardized, many vocational colleges are based on traditional teaching course, did not reflect the speciality and characteristic of foreign nursing. The core ability of nursing mainly includes eight aspects, the specific are shown as below. 


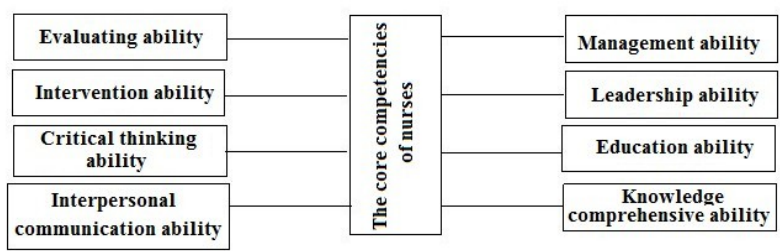

Figure 1. The main aspects of the core competencies of nurses

As shown in Figure 1, the core competencies of nurses including assessment, intervention ability, communication ability, critical thinking ability, interpersonal ability, management ability, leadership, education and knowledge comprehensive ability. But the nurses with the core competence is inseparable from the English education they get from vocational college, and vocational English teaching must serve for the professionals, it has become China's higher occupation education consensus.

\section{B. Analysis on vocational foreign-related nursing RICH course}

RICH is a course developed on the basis of foreign language education reform of RICH in the Zhejiang Normal University Institute. RICH is an acronym, it is composed of the acronym of the following four words: Research based, Integrated curriculum, Cooperative learning , Humanistic outcome, above four aspects constitute the exploration of foreign language teaching and learning curriculum practice. The process is shown as below.

As shown in Figure 2, RICH opened the most valuable exploration of higher vocational nursing English teaching, it makes the foreign language teaching jump out of the narrow field of view from more basic knowledge and communicative competence, to return English learning to a tool, to explore the international vocational nursing students' all-round development and core ability, making the classroom activity from the Institution consciousness control to the social activities with mutual respect, discuss and understanding.

\section{English learning of vocational foreign-related nursing RICH course}

The university English Teaching of nursing specialty in higher vocational colleges should take the initiative and specialty construction standards, serve for professional personnel training, the traditional simple imparting knowledge of English should change to cultivate the core competence of nurses, this is the only way to reform university English teaching in higher vocational education. The current higher vocational nursing English teaching are subjected to knowledge and utilitarian purpose, vocational nursing students in university English classroom only serve the language knowledge and skills as a legitimate learning object, in such teaching structures, students are not main thought body, but the English subject shaping object.

Higher vocational foreign-related nursing students as thinkers of the natural attribute and core competence for nurses in natural breed, become the ultimate vision of RICH education field. The educational connotation is originates from the life world, and in a fair, sincere words in naturally occurring. So higher vocational foreign language teaching can be regulated by three different intellectual interest drive, namely technical interest, strategic interest and the emancipatory interest for the purpose of understanding. The specific are shown as below.

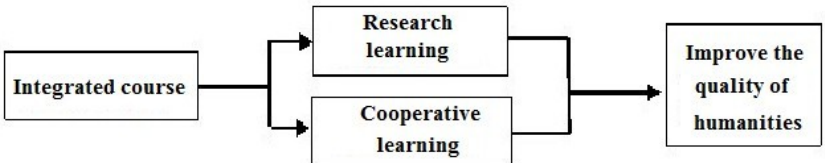

Figure 2. The learning process of foreign nurses RICH course in vocational

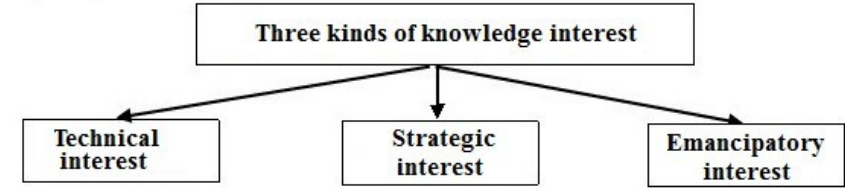

Figure 3. The knowledge interest schematic diagram of foreignrelated nursing language teaching in vocational

As shown in Figure 3, the foreign language teaching of higher vocational nursing students have three kinds of intellectual interest, including technical interest focus on language knowledge, language into a at a technical level can be operated in the word and sentence, unit and listening, speaking, reading, writing and translation skills; strategic interest focus communication ability, have stronger purpose, learn a language is to achieve a utilitarian purpose; emancipatory interest refers to the learner does not provide social goal, but in the surrounding business understanding of form a profound insight and critical significance of independence. Higher vocational foreign language teaching can be in more than three different intellectual interests, but only the last interest can also 
have three kinds of characteristics of knowledge, namely in the form of understanding at the same time, achieving a social purpose and mastering the use of language skills.

\section{Under the network environment in Vocational foreign-related nursing students RICH program demonstration}

The theoretical basis of foreign-related nursing RICH course in vocational under the network environment

Students' life have all kinds of connections with network. In such a information age represented by multimedia and network technology, the student 's experience of the world will be with the help of modern multimedia technology and network communication technology to build multimedia network learning environment, the use of modern information technology to accept and deal with information has also become the social members' basic requirements for social development. Therefore, Ministry of education made 2000 " Basic requirements for Higher Vocational Education English teaching(for trial implementation ) " document made clear in the English Teaching of Higher Vocational Education " to actively introduce and use of computer multimedia, network technology and other modern means of teaching, stimulate the students' enthusiasm and consciousness in learning English ". From life world RICH teaching mode should break through time and space constraints, make full use of modern educational technology and teaching resources of the network, provide students with a good learning environment, building a network environment to students, teachers mainly supplemented by the opening teaching mode, from which students from passive state to the pursuit of knowledge, to cultivate self-learning ability and ability to solve problems independently.

Empirical analysis on foreign-related nursing RICH course in Vocational under the network environment

In order to verify the RICH course in Higher Vocational Colleges under the network environment of foreign-related nursing, the effect of students nurses core competence development may have, we take Ningbo vocational college nursing students as the research object,make application of the case study by the narrative strategy, the research orientation, in foreign language teaching by carrying out RICH curriculum practice, through interviewing, classroom behavior observation and the reflective diary and other research data collection methods to collect research object data which the core competencies of nurses changed . Under the network environment in vocational nursing students : An Empirical Analysis of foreign RICH course is divided into three major parts, the specific process is shown in the following table.

Table 1 Empirical analysis on foreign-related nursing RICH course in Vocational under the network environment

\begin{tabular}{|c|c|c|}
\hline Stage & Project name & Key words \\
\hline $\begin{array}{c}\text { Stage } \\
1\end{array}$ & Preparation & On the theoretical basis of research; \\
\hline \multirow[t]{4}{*}{$\begin{array}{c}\text { Stage } \\
2\end{array}$} & \multirow[t]{4}{*}{$\begin{array}{l}\text { Design and } \\
\text { implementation scheme }\end{array}$} & $\begin{array}{l}\text { (1)Rational subgroup, in order to } \\
\text { carry out the group cooperation; }\end{array}$ \\
\hline & & $\begin{array}{l}\text { (2) Introduction of RICH course, make } \\
\text { the students subjective acceptance } \\
\text { of RICH course; }\end{array}$ \\
\hline & & $\begin{array}{l}\text { (3)Design on the topic research as the } \\
\text { center of teaching activities; }\end{array}$ \\
\hline & & (4)Design of rational evaluation rubric; \\
\hline $\begin{array}{c}\text { Stage } \\
3\end{array}$ & $\begin{array}{l}\text { Experimental data } \\
\text { collection and analysis }\end{array}$ & $\begin{array}{l}\text { Data collection under the network environment, to understand the changes of RICH curriculum students } \\
\text { before and after in the core competence for nurses, and analyze the reasons behind the changes of core } \\
\text { competence for nurses. }\end{array}$ \\
\hline
\end{tabular}

As shown in Table 1, under the network environment in vocational foreign-related nursing students RICH empirical analysis process is divided into three stages. Firstly, preparing main literature at home and abroad, finding out the core competencies of nursing under the network environment RICH research; in the second phase study, using reflective diary, classroom behavior observation and interviews, thereby collecting subjects in the network environment in RICH course of nursing core competencies changing data; third stages is experimental data collection and analysis. Collection of reflective diary, classroom behavior observation and interview data, understand network environment RICH curriculum and changes of student core nursing ability, and the analysis of the core competencies of nurses is behind the change. In the analysis of the specific process of the difference between different students may have a constant difference to illustrate, therefore, is a parameter to be estimated. The core competencies of nurses in a general form is[4]:

$$
\mathrm{y}_{\text {it }}=\alpha_{\mathrm{i}}+x_{i t} \beta_{i}+u_{i t} \quad \mathrm{i}=1,2, \ldots, \quad \mathrm{N} ; \mathrm{t}=1,2, \ldots, \mathrm{T}
$$


In formula (1) wherein, ${ }_{i t}$ for the core competencies of nurses is not a fixed change, when the $\mathrm{E}\left(u_{i t}\right)=0, \operatorname{Var}\left(u_{i t}\right)=\sigma_{u}^{2}$, and $\mathrm{u}_{i t}$ and $\mathrm{x}_{\mathrm{it}}$ is not related, in the operation, in order to analyze the convenient,therefore, we wrote formula (1) in rectangular form. The $y_{i}$ and $x_{i}$ respectively for the international higher vocational nursing students' T observation vectors and matrices, $\mathrm{u}_{\mathrm{i}}$ is the $\mathrm{T} \times 1$ core competencies of nurses is not fixed in the vector. Type (1) can be written as[5]:

$$
y_{i}=i \alpha+\mathrm{X}_{i} \beta+u_{i}
$$

In formula (2) in the following aspect:

$$
i=\left(\begin{array}{c}
1 \\
1 \\
\vdots \\
1
\end{array}\right)_{T \times 1} ; \beta=\left(\begin{array}{c}
\beta_{1} \\
\beta_{2} \\
\vdots \\
\beta_{\mathrm{K}}
\end{array}\right)_{\mathrm{K} \times 1}
$$

$\mathrm{y}_{\mathrm{i}}$ and $x_{i}$ and the $\mathrm{u}_{\mathrm{i}}$ definition and (11.3) in the definition is the same, in the network environment for panel survey design, network environment panel survey, prepare a summary report, summary report and the evaluation of present students to explore knowledge, mutual help and cooperation between teachers and students, transform the traditional one-way or two-way communication between students to more exchanges, make the students as the presence of natural persons of cultivating the assessment and intervention skills, communication skills, critical thinking skills, interpersonal skills, management skills, leadership, education and knowledge comprehensive ability of nursing core competencies natural breed was incorporated into the curriculum system. The whole analysis of the core competencies of nurses can be varied with the matrix representation for[6]:

$$
\left(\begin{array}{c}
y_{1} \\
y_{2} \\
\vdots \\
y_{n}
\end{array}\right)=\left(\begin{array}{cccc}
i & 0 & \cdots & 0 \\
0 & i & \cdots & 0 \\
\vdots & \vdots & \vdots & \vdots \\
0 & 0 & \cdots & i
\end{array}\right) \times\left(\begin{array}{c}
\alpha_{1} \\
\alpha_{2} \\
\vdots \\
\alpha_{n}
\end{array}\right)+\left(\begin{array}{c}
\mathrm{X}_{1} \\
\mathrm{X}_{2} \\
\vdots \\
\mathrm{X}_{n}
\end{array}\right) \beta+\left(\begin{array}{c}
u_{1} \\
u_{2} \\
\vdots \\
u_{n}
\end{array}\right)
$$

Further definitions[7]:

$$
\mathrm{D}=\left(d_{1}, d_{2}, \cdots, d_{n}\right)=\left(\begin{array}{cccc}
i & 0 & \cdots & 0 \\
0 & i & \cdots & 0 \\
\vdots & \vdots & \vdots & \vdots \\
0 & 0 & \cdots & i
\end{array}\right)
$$

$d_{i}$ is the first $\mathrm{i}$ unit virtual variables, it is a nT vector, thus $\mathrm{D}$ is a matrix of $\mathrm{nT} \times \mathrm{n}$, in the teaching process, teachers can provide the students the necessary learning support service by telephone, email, QQ group and other forms, so as to cultivate students' core competencies of nursing, and ( 5) can be write for[8]:

$$
\mathrm{y}=\mathrm{D} \alpha+\mathrm{X}_{\mathrm{i}} \beta+\mathrm{u}_{\mathrm{i}}
$$

After studying the network environment of RICH course a semester, data display on the core competencies of nurses obtained apparent progress. There are several steps in main activities in research(identifying the topic, access to information, report preparation, classroom, review summary report), a student wrote at the reflective diary: we jump out of the textbook, in order to group as a unit in accordance with their interest in determining topic, walk into the life and understand life. We use the web to query the information which is related to the topic of English articles, English video, using the network communication, such as MSN, QQ and EMAIL, consult a foreign friend and teacher, in the process, we retrieve the information and our ability can be obtained through exercising, reading foreign language information level get a promotion, at the same time through group discussion, we learn to question, to analyze and solve problems.

\section{Empirical validation of foreign-related nursing RICH course in vocational under the network environment}

In the research process, observing the situation of study and students' feedback, so as to adjust strategy to achieve better results constantly. On the analysis of changes of nurses in the core competencies. T test cannot be used normally, because of the use of t test location parameter equals or not equal to a constant, but the test analysis of the core competencies of nurses change original hypothesis is[9]:

$$
\mathrm{H}_{0}: \alpha_{i}=\alpha_{j}(i \neq j)
$$


In this case, similar to the regression equation of overall significance test, is it right? That regression coefficients reach to zero simultaneously, it can use F statistic to test. under the original hypothesis condition, F statistic[10]:

$$
\mathrm{F}=\frac{\left(R_{u}^{2}-R_{p}^{2}\right) /(n-1)}{\left(1-R_{u}^{2}\right) /(n T-n-K)}
$$

Amenable to molecular degrees of freedom for the $n-1$, denominator degrees of freedom for the $n T-n-K$ F distribution. Type $\mathrm{R}_{u}^{2}$ for unconstrained model decision coefficient, $\mathrm{R}_{p}^{2}$ for the constraint model coefficient of determination, constraint is the original hypothesis. When the F statistic value is greater than a critical value, reject the null hypothesis, namely the core competencies of nurses change tends to be good; when the F statistic value is less than the critical value, which can not reject the null hypothesis, namely the core competencies of nurses change tends to be the bad aspect.

\section{Conclusion}

The results showed, the RICH under the environment of network course can improve the international higher vocational nursing students' core competence effectively. Students use the cyber source, in order to understand affairs as the interest in learning, while the acquisition of language skills and scientific research ability, comment ability, critical thinking ability, knowledge integration ability, interpersonal skills, management skills and leadership ability as the core competencies of nurses. Under the network environment of the RICH course can be active and vocational nursing specialty construction standards, professional personnel training services, the traditional simple imparting knowledge of English to cultivate the core competence of nurses who change, this is the only way which the university English teaching reform needed be passed in Higher Vocational education.

\section{Acknowledgments}

This paper belongs to the achievement of the education technology programming projects of Zhejiang province in 2012 with project No. JB157.

\section{References}

[1] $\mathrm{Xu}$ Ying.Foreign nursing students' learning of English thinking[J].The Guide of Science \& Education,2011(17):43-45

[2] Xu Hongli,Bai Mengqing.Foreign students cross cultural nursing ability[J].Journal of Hubei Polytechnic Institute,2009(02):32-34

[3] Liao Yahui.According to the characteristics of medical English in international higher vocational nursing students develop learning strategies[J].Journal of Yueyang Vocational Technical College,2011,26(03):35-37

[4] Lu Siying,Qin Bowen.Improve foreign-related nursing students of nursing ability of English listening and speaking teaching method[J].Health Vocational Education,2010,28(22):54-55

[5] Hou Yaqiong.Discussion on higher vocational students employment prospect and direction of foreign nursing[J].Work \& Studying Abroad,2012(01):61-62

[6] Liu Ming,Kunaiktikul W,Senaratana W.Chinese registered nurse framework [J]. Chinese Journal of Nursing,2010(4):91-94

[7] Wu Yi'an.Chinese college English teachers' education and development research[M].Foreign Language Teaching and Research Press,2011:385

[8] Ying Danjun.Group learning : the panel discussed the organization and operation[J].Language Curriculum and Teacher Development,2010(8):107-109

[9] $\mathrm{Wu}$ Zongjie,Huang Aifeng.Language curriculum and teacher development-RICH education field of vision[M].Beijing:People's Education Press,2010(15):294

[10] Lenburg C.The framework, concepts and methods of the competency outcomes and performance assessment (COPA) model [J]. Journal of Nursing Issues, 2009,30(9):29-32 